\title{
Instructions Affect Reaction Time Variability: Evaluation by Event-Related Potentials
}

\author{
Tomofumi Fukuda, Masayuki Shimono*, Ayako Senju, Masahiro Ishii, Ryouta Igarashi, \\ Koichi Kusuhara
}

Department of Pediatrics, University of Occupational and Environmental Health, Kitakyushu, Japan

Email: *shimono@med.uoeh-u.ac.jp

How to cite this paper: Fukuda, T., Shimono, M., Senju, A., Ishii, M., Igarashi, R. and Kusuhara, K. (2017) Instructions Affect Reaction Time Variability: Evaluation by Event-Related Potentials. Journal of Behavioral and Brain Science, 7, 95-110. https://doi.org/10.4236/jbbs.2017.73010

Received: January 18, 2017

Accepted: March 3, 2017

Published: March 6, 2017

Copyright $\odot 2017$ by authors and Scientific Research Publishing Inc. This work is licensed under the Creative Commons Attribution-NonCommercial International License (CC BY-NC 4.0). http://creativecommons.org/licenses/by-nc/4.0/

\begin{abstract}
Auditory change detection studies have shown that a repetition effect occurs when the response-stimulus interval is less than 500 ms. However, this response repetition effect is variable. Forty healthy young subjects were asked to respond to target stimuli pertaining to event-related potentials as quickly and accurately as possible (10\% target, inter-stimulus interval: $1500 \mathrm{~ms})$. Reaction time (RT) for the targets was measured with electroencephalography. RT was found to be the fastest for the second instance of repeated targets and targets that appeared after 17 or more successive non-targets $(p<0.001)$. The longest P3 latencies and smallest P3 amplitudes were observed for the second instance of repeated targets; conversely, the shortest P3 latencies and largest P3 amplitudes were observed for targets that appeared after 17 or more successive non-targets $(\mathrm{p}<0.001)$. All target stimuli were accompanied by a $-0.9 \mu \mathrm{V}$ baseline negative shift of the frontal scalpelectroencephalography $100 \mathrm{~ms}$ before the upcoming stimulus, suggesting that SPN was observed after every target stimulus. The non-target stimuli immediately after target were accompanied by MMN. Therefore, we concluded that subjects prioritized instructions pertaining to quicker response than those pertaining to accuracy. That explains RTs of second instance of repeated target are one of the fastest and how mistakes occur for non-target immediately after target stimulus. Negative baseline shifts detected by electroencephalography in this variable task with target and non-target event-related potentials provide key elements in the understanding of auditory responses.
\end{abstract}

\section{Keywords}

Auditory Response, Response Repetition, Mismatch Negativity, Contingent Negative Variation 


\section{Introduction}

A considerable number of experiments have demonstrated that reaction time (RT) on trial $\mathrm{n}$ is faster when the same stimulus is presented as trial $\mathrm{n}-1$ than when a different stimulus is presented; this phenomenon is known as the repetition effect (RE) [1]-[10]. Some experiments showed that RE was observed when response-stimulus interval (RSI) was shorter than $500 \mathrm{~ms}$ in choice tasks [4] [7] [8], and some other experimenters suggested that RE was observed when RSIs were $2000 \mathrm{~ms}$ or longer [2] [3] [5]. RE was explained using two mechanisms: automatic facilitation and subjective expectancy [4] [5]. In Remington's 70:30 choice tasks experiment [11], RE was prominently observed using low probability stimuli. The results suggested that the target probabilities also affected RE. Therefore, we assume that there are other factors affecting RE, including subjects' attention or the instructions received by them on how to respond to target stimuli. If subjects are instructed to respond to target stimuli as quickly as possible, information process related to response will be priming and bypassing some cognitive stages [12]. These processes were supported the theory of neural repetition effect as reduced neural activity by Baldeweg [9] and neural network would change when neural activity reduced by Grill-Spector et al. [10]. However, the mechanisms underlying RE are not fully understood.

When subjects are instructed to respond to an upcoming stimulus as quickly as possible, subjects' electroencephalography (EEG) current, shifts to negative polarity [13] [14] [15]. Therefore, if we choose an appropriate inter-stimulus interval (ISI) or stimulus onset asynchrony (SOA), we can analyze EEG current shifts during the oddball task. Brunia [14] proposed the following three types of negative shifts to precede when subjects expected an upcoming stimulus: contingent negative variation $(\mathrm{CNV})$, promoter lateralized readiness potential (LRP), and stimulus preceding negativity (SPN). When the CNV amplitude becomes larger, RTs become faster proportionally. The SPN reflects attention processes regarding the upcoming stimulus. These potentials appear at $400-500 \mathrm{~ms}$ after pre-stimulus [15]; therefore, RE may correlate with these event-related potential (ERP) responses.

There are other studies for stimulus evaluation. Mismatch negativity (MMN), an ERP to represent small changes in the acoustic environment, engages an automatic auditory change detection mechanism. When subjects detect an unexpected deviant stimulus in a sequence of standard stimuli, their EEG generates MMN [16] [17]. When MMN appears in a sequence of choice tasks, we believe that subjects conclude the stimulus to be deviant. Thus, with these ERPs, we are able to more precisely elucidate RE.

The N1 and P3 component of ERP is an another electrophysiological index of information processing for higher level of brain function that appears approximately 100 - $300 \mathrm{~ms}$ after stimulus presentation [18] [19] [20] [21]. Previous studies showed that N1 appeared for both target and non-target stimuli. Thus, Lange, Rösler, and Röder [22] and Barry [21] suggested that N1 appears when subjects encode the stimulus, and this ERP has an exogenous nature. There are 
three types of P3: P3a, P3b, and nogoP3 [23] [24]. P3a is elicited by novel stimuli, displays frontocentral scalp distribution, has shorter latency than P3b, and is rapidly habituated. It is supposed to reflect subjects' surprise and/or attention process. P3b is elicited by target stimuli, displays centroparietal scalp distribution, and is typically related to the target cognition process [18] [25]. NogoP3 is related to the withholding response process [21]. Thus, P3s have an endogenous nature. $\mathrm{P} 3$ shall be used in place of $\mathrm{P} 3 \mathrm{~b}$ hereafter.

Only a few ERP experiments with RE using an oddball task provide insights pertaining to how the instructions provided to subjects work and how does the stimulus probability affect the RE mechanism [26] [27] [28]. If we can analyze the ERPs presented above using stimulus sequences, we will be able to more precisely examine RE and the instruction mechanisms. Therefore, the purpose of this study is to elucidate the mechanism underlying the target repetition effect via an auditory oddball task (target probability: 10\%, ISI: $1500 \mathrm{~ms}$ ).

We analyzed the following points using the auditory oddball task:

1) Changes in RT for each target, categorized by preceding non-target repetitions;

2) Changes in target $\mathrm{N} 1$ and $\mathrm{P} 3$ latencies and amplitudes and negative EEG shifts before the upcoming stimulus, categorized by preceding non-target repetitions;

3) Changes in ERPs of non-targets and the area of negative EEG shifts, categorized by preceding non-target repetitions.

These approaches allowed us to examine how the instructions to the subjects and target and non-target sequences affect RE in this study more precisely than previous studies.

\section{Subject and Method for Experiment 1}

Forty healthy subjects ( 22 males and 18 females) with a mean age of 22.9 years (range: 19 - 27 years) participated in this study. All subjects were students from the University of Occupational and Environmental Health, Japan, right-handed, and not trained for this type of an experiment. They were healthy, which meant that they did not regularly take medicines or suffer with psychological problems, as examined during the annual college health check programs, and have a history of developmental or hearing impairments. Prior to the experiment, all subjects provided their written informed consent, and the study was reviewed and approved by the Ethics Committee of the University of Occupational and Environmental Health, Japan. We used auditory oddball task and analyzed the target data in Experiment 1. The subjects listened for target tones (10\%) among a series of frequent non-target tones (90\%). The targets and non-targets were presented pseudo-randomly with a constant stimulus onset asynchrony (SOA) of $1500 \mathrm{~ms}$. Subjects sat on a comfortable chair in an electrically shielded and sound attenuated room. They listened for tones and fixed their eyes on a mark presented at the center of the NEC MB-72 computer monitor placed at $100 \mathrm{~cm}$ in front of them, while keeping their eye movement and blinking to a minimum. Subjects 
were instructed to press a button after hearing the target tone (RT) with their dominant hand as quickly as possible and to be as accurate as possible. The auditory oddball task contained target repetition, and we could examine the mechanisms underlying RE. We examined the RT, ERP components (N1 and P3), and EEG current shifts for the target categories. The trigger pulses of the auditory oddball task were generated using a Multistim Box (MB)-72 (NEC MEDICAL SYSTEM, Japan). The target and the non-target trigger-pulses were presented at $50 \mathrm{~ms}$ plateau bursts with rise and fall time of $10 \mathrm{~ms}$ each. The tones are presented $50 \mathrm{~dB}$ HL with two SS-F 6000 speakers (SONY, Japan) placed at left and right side of the computer each. The EEGs and EOGs were amplified using a Synax 1200 (NEC Co, Tokyo, Japan) with $0.02-30 \mathrm{~Hz}$ online filters. RTs, EEGs ( $\mathrm{Fz}, \mathrm{Cz}$, and $\mathrm{Pz}$ referenced to linked earlobes), EOGs, and trigger pulses for each stimulus were simultaneously recorded using a data recorder (Dr-M3 MK2, TEAC Co. Tokyo, Japan). The sampling rate was $512 \mathrm{~Hz}$ for each channel. Ag-AgCl electrodes were used according to the $10-20$ system in reference to linked earlobes. Forehead electrodes were grounded. EEGs were analyzed using Eplyzer II software (Kissei Comtec, Matsumoto, Japan) for Windows 7 SP3.

Subjects were allowed an initial half-minute practice period to familiarize themselves with the task. Subsequently, they participated in two 10.5-min experimental blocks separated by a 5 -min break, comprising 42 target stimuli per block. The target and the non-target tones $(1000 \mathrm{~Hz}$ and $2000 \mathrm{~Hz}$, respectively) were counterbalanced across blocks and subjects.

Electrooculograms (EOGs) were recorded through electrodes placed $1 \mathrm{~cm}$ from the left outer can thus and $1.5 \mathrm{~cm}$ under the left suborbital region. These two electrodes enabled us to monitor saccadic eye movements and blinking [28]. RTs, EEGs, EOGs, and stimulus trigger pulses for each target were simultaneously recorded using a data recorder. RT and EEG for targets and the EEG current shifts were averaged for each subject and grand averaged using Eplyzer II software. Measuring the data with only three electrodes prevented us from investigating LRPs. Each EEG for target stimulus was measured from $100 \mathrm{~ms}$ before the stimulus pulse (pre-stimulus baseline) to $1400 \mathrm{~ms}$ after the stimulus pulse. We grouped the target sequences into six categories according to the number of preceding non-targets [TT, $\mathrm{N}_{1-4} \mathrm{~T}, \mathrm{~N}_{5-8} \mathrm{~T}, \mathrm{~N}_{9-12} \mathrm{~T}, \mathrm{~N}_{13-16} \mathrm{~T}$, and $\mathrm{N}_{\geq 17} \mathrm{~T}$; hereafter, stimulus sequences are denoted with $\mathrm{T}$ (target) and $\mathrm{N}$ (non-target) and a subscript representing the number of stimuli]. For instance, $\mathrm{N}_{1-4} \mathrm{~T}$ represents a target ERP following one to four non-target repeats. Averaging each category of EEG responses, we defined $\mathrm{N} 1$ as the negative peak between $50 \mathrm{~ms}$ and $149 \mathrm{~ms}$ after the target or non-target stimulus pulse. We defined P3 as the positive peak between $250 \mathrm{~ms}$ and $500 \mathrm{~ms}$ after the target stimulus pulse. The N1 and P3 amplitudes were measured relative to the maximum negative or positive value from the pre-stimulus baseline.

Negative EEG shifts serve as a marker for the upcoming stimulus. We calculated the degree of negative shift by integrating the area between the pre-stimulus baseline and ERP shift from $600 \mathrm{~ms}$ to $100 \mathrm{~ms}$ before the upcoming sti- 
mulus in accordance with negative and positive polarities.

Because we focused on the RE mechanism, we chose an extremely low target probability. Consequently, obtaining the necessary number of stable EEG responses was difficult for sequential target ERPs. Thus, we grouped the target sequences into six categories and got 14 EEG responses for each target category. More than 30 EEG responses are recommended for creating valid averaged ERPs [29]. To minimize the potential adverse impact from a low number of EEG responses, we decided to study 40 subjects rather than the typical 10 to 15 subject range. Increasing the number of subjects in this way does not solve the problem pertaining to the low number of target EEG responses, but it potentially raises the validity of the grand averaged waveforms of the target ERP.

Omission error was set at pressing the button $600 \mathrm{~ms}$ after target pulse or not pressing the button. EOG amplitudes over $50 \mu \mathrm{V}$ were treated as artifacts.

A repeated-measures analysis of variance (ANOVA) was used to compare the difference among categories of TT, $\mathrm{N}_{1-4} \mathrm{~T}, \mathrm{~N}_{5-8} \mathrm{~T}, \mathrm{~N}_{9-12} \mathrm{~T}, \mathrm{~N}_{13-16} \mathrm{~T}$, and $\mathrm{N}_{\geq 17} \mathrm{~T}$. When ANOVA revealed significant differences, we used Scheffe's analysis to examine the differences between the categories. P less than 0.05 was considered significance.

\section{Result of Experiment 1}

\subsection{Reaction to the Target Stimulus}

All subjects indicated that the auditory oddball task was quite easy to perform and that they understood that the target stimuli rarely appeared. As a result, we observed no omission error. There were no significant differences in artifacts between the two blocks; the percentage of artifacts was $9.9 \pm 0.3$ in the first block and $9.3 \pm 0.2$ in the second block. Therefore, the data from blocks 1 and 2 were analyzed in combination.

We compared RTs of the six target categories. The number of RT and EEG responses obtained for each target category were $10.1 \pm 0.2(\mathrm{TT}), 11.9 \pm 0.2$ $\left(\mathrm{N}_{1-4} \mathrm{~T}\right), 9.8 \pm 0.2\left(\mathrm{~N}_{5-8} \mathrm{~T}\right), 10.2 \pm 0.2\left(\mathrm{~N}_{9-12} \mathrm{~T}\right), 10.3 \pm 0.3\left(\mathrm{~N}_{13-16} \mathrm{~T}\right)$, and $8.1 \pm 0.2$ $\left(\mathrm{N}_{\geq 17} \mathrm{~T}\right)$. The data are presented as mean \pm SE. Significant RT differences $\left(\mathrm{F}_{(5,35)}=\right.$ 11.1, $\mathrm{p}<0.001$, epsilon $=0.733$ ) are illustrated in Figure $1(\mathrm{a})$. Scheffe's analysis revealed a significant RT difference between TT (306 $\pm 7 \mathrm{~ms})$ and $\mathrm{N}_{1-4} \mathrm{~T}(330 \pm 8$ ms; $\mathrm{p}=0.021)$ and between $\mathrm{N}_{1-4} \mathrm{~T}$ and $\mathrm{N}_{\geq 17} \mathrm{~T}(304 \pm 5 \mathrm{~ms} ; \mathrm{p}=0.037)$. RTs for the other categories $\left(\mathrm{N}_{5-8} \mathrm{~T}: 315 \pm 6 \mathrm{~ms} ; \mathrm{N}_{9-12} \mathrm{~T}: 314 \pm 6 \mathrm{~ms} ; \mathrm{N}_{13-16} \mathrm{~T}: 313 \pm 7 \mathrm{~ms}\right)$ did not significantly differ from that for the $\mathrm{N}_{1-4} \mathrm{~T}$ category. These results showed that RTs were fastest for the TT and $\mathrm{N}_{\geq 17} \mathrm{~T}$ categories and slowest for the $\mathrm{N}_{1-4} \mathrm{~T}$ category.

To elucidate the mechanism underlying the RT difference between the TT and $\mathrm{N}_{1-4} \mathrm{~T}$ categories, we divided the $\mathrm{N}_{1-4} \mathrm{~T}$ category into subcategories representing each number of intervening non-targets and compared their RTs with those for the TT category. Figure 1(b) illustrates that RTs for the TT category were the fastest $\left(\mathrm{F}_{(4,36)}=8.4, \mathrm{p}<0.001\right.$, epsilon $\left.=0.883\right)$ and those for the $\mathrm{N}_{1} \mathrm{~T}$ category were the slowest $(342 \pm 10 \mathrm{~ms}, \mathrm{p}=0.008)$. RTs for the $\mathrm{N}_{2} \mathrm{~T}(324 \pm 7 \mathrm{~ms}), \mathrm{N}_{3} \mathrm{~T}$ 


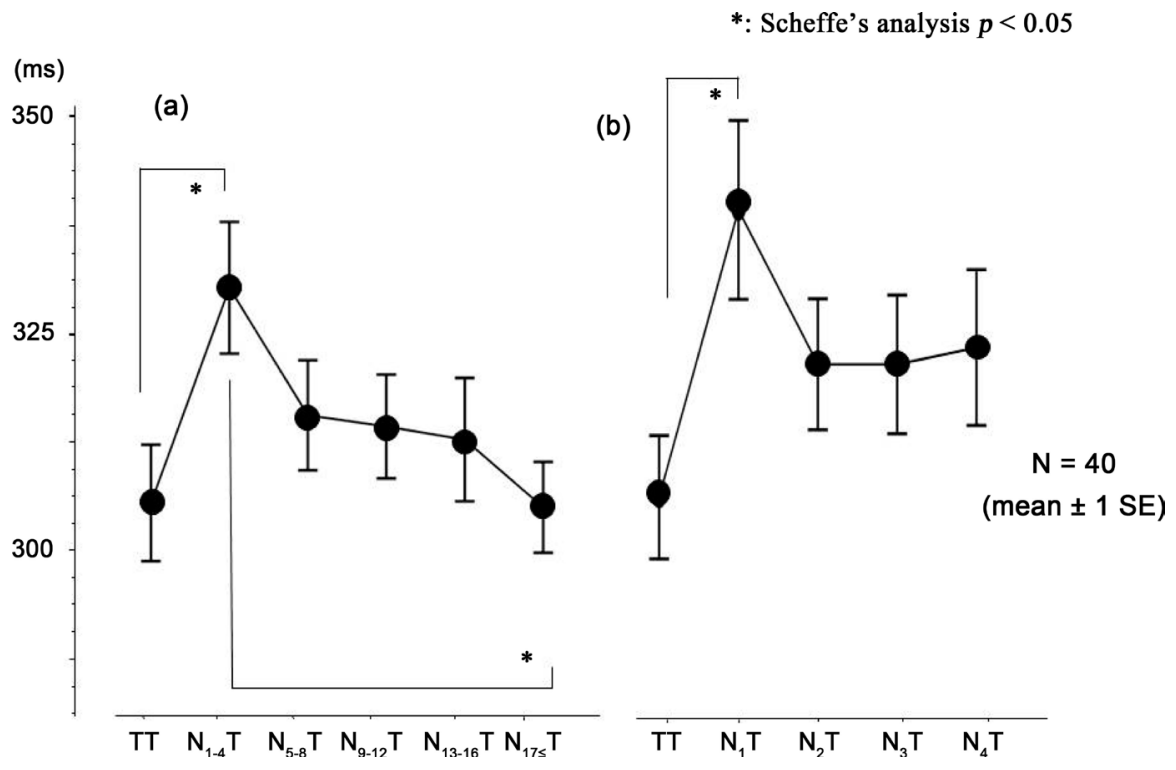

Figure 1. Reaction time by the number of immediately preceding non-target repeats. Mean reaction times (RTs, $\mathrm{N}=40$ ) for six target categories (a) and subcategories (b). (a) RTs to the second instance of repeated targets (TT) and to targets that appeared 17 or more successive non-target repeats $\left(\mathrm{N}_{\geq 17} \mathrm{~T}\right)$ are the fastest. When target tone is appeared after one to four non-target repetitions $\left(\mathrm{N}_{1-4} \mathrm{~T}\right)$, RT is the slowest. As the number of intervening non-targets increase, RTs becomes gradually faster than those in the $\mathrm{N}_{1-4} \mathrm{~T}$ category. (b) Within the TT and $\mathrm{N}_{1-4} \mathrm{~T}$ categories, RTs of the $\mathrm{T}_{1} \mathrm{~N}$ sequence are the slowest. Bars indicate standard error.

(323 $\pm 8 \mathrm{~ms})$, and $\mathrm{N}_{4} \mathrm{~T}(325 \pm 9 \mathrm{~ms})$ categories ranged between those for the TT and $\mathrm{N}_{1} \mathrm{~T}$ categories. These results indicated that the slowest RTs observed for the $\mathrm{N}_{1-4} \mathrm{~T}$ category were attributable to the RT for the $\mathrm{N}_{1} \mathrm{~T}$ category.

\subsection{N1 and P3 Latencies and Amplitudes}

Figure 2(a) shows grand averaged ERPs of the six target categories. Statistical methods are the same as above. Although no significant differences in latency or amplitude were observed for the N1 component among the categories, amplitudes were significantly different among the sites $\left(\mathrm{F}_{(2,38)}=68.6, \mathrm{p}<0.001\right.$, epsilon $=0.774)$. The $\mathrm{N} 1$ amplitude at $\mathrm{Fz}(-7.7 \pm 0.5 \mu \mathrm{V})$ was larger than that at $\mathrm{Pz}(-5.8$ $\pm 0.5 \mu \mathrm{V} ; \mathrm{p}=0.022)$. The $\mathrm{N} 1$ amplitudes at $\mathrm{Cz}(-7.4 \pm 0.5 \mu \mathrm{V})$ and $\mathrm{Pz}$ showed borderline significance $(\mathrm{p}=0.065)$. The $\mathrm{P} 3$ latencies were significantly different among the categories $\left(\mathrm{F}_{(5,35)}=13.2, \mathrm{p}<0.001\right.$, epsilon $\left.=0.522\right)$ but not different among the sites. The $\mathrm{P} 3$ amplitudes were significantly different among the categories $\left(\mathrm{F}_{(5,35)}=22.1, \mathrm{p}<0.001\right.$, epsilon $\left.=0.750\right)$ and the sites $\left(\mathrm{F}_{(2,38)}=72.6, \mathrm{p}<\right.$ 0.001 , epsilon $=0.606)$. Using Scheffe's analysis (Figure $2(\mathrm{~b}-1)$ and Figure 2(b-2)), the P3 latencies for the target grew shorter (P3 latencies of TT and $\mathrm{N}_{\geq 17} \mathrm{~T}$ at $\mathrm{Pz}$ are $358 \pm 6$ and $330 \pm 4 \mathrm{~ms}$, respectively) and the amplitudes grew larger ( $\mathrm{P} 3$ amplitudes of TT and $\mathrm{N}_{\geq 17} \mathrm{~T}$ at $\mathrm{Pz}$ are $7.6 \pm 0.8$ and $14.4 \pm 0.9 \mu \mathrm{V}$, respectively) as the number of non-targets preceding the target increased. These results show that there was a surprising difference between the ERPs of the TT and $\mathrm{N}_{\geq 17} \mathrm{~T}$ categories, although their RTs were almost the same. 


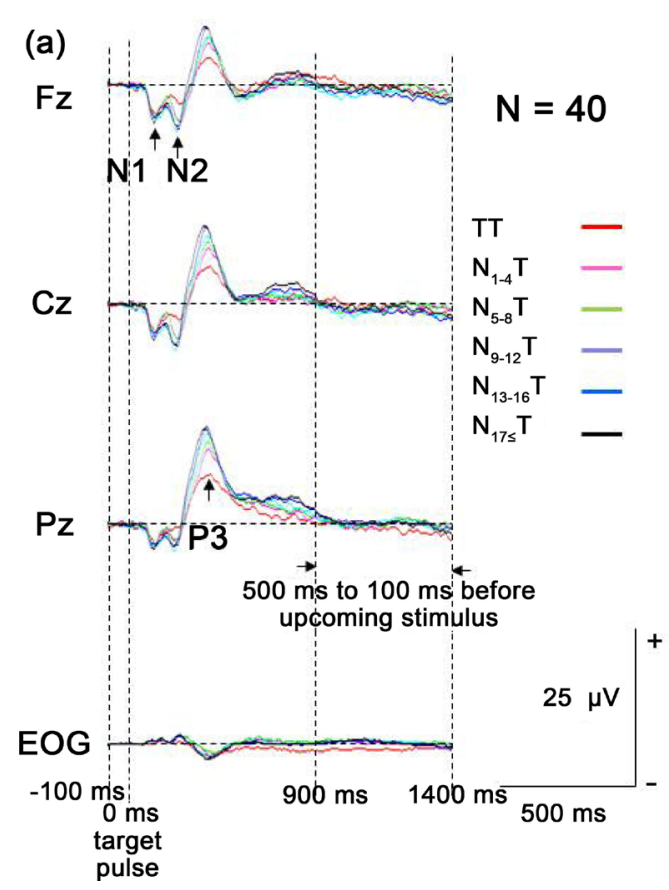

(b-1)

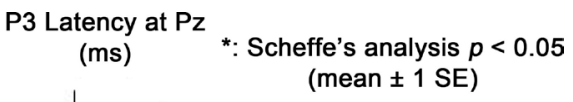

Figure 2. Grand Averaged ERP of target stimuli categorized by immediately preceding non-target repeats. (a) Grand averaged target ERPs $(\mathrm{N}=40)$ for the six target categories. P3 latencies and amplitudes for the TT category are the longest and the smallest. The negative shifts from $600 \mathrm{~ms}$ to $100 \mathrm{~ms}$ before upcoming stimulus for each category are front central dominant and almost the same amplitude. Hence, the amplitude of the EOG is much smaller than the EEG responses, and we can say that the EOG is influenced by the EEG responses. (b-1) P3 latencies become faster and (b-2) P3 amplitudes become larger as the number of preceding non-target repeats increase.

\subsection{EEG Current Shifts after Each Target Categories}

We examined the areas of negativity between $600 \mathrm{~ms}$ and $100 \mathrm{~ms}$ before the upcoming stimulus. We found negative EEG shift in every target category at Fz and $\mathrm{Cz}$ (Figure 2(a)). ANOVA showed no significant differences in the area among the target categories and interaction between the categories and sites. The areas of negative EEG shift between $600 \mathrm{~ms}$ and $100 \mathrm{~ms}$ before the upcoming stimulus were significantly different, depending on the sites $\left(\mathrm{F}_{(2,38)}=10.9, \mathrm{p}<0.001\right.$, epsilon $=0.687)$. Scheffe's analysis showed that the area of negativity at $\mathrm{Fz}(-0.9 \pm$ $0.1 \mathrm{mV} \cdot \mathrm{ms})$ was larger than that at $\mathrm{Pz}(-0.2 \pm 0.2 \mathrm{mV} \cdot \mathrm{ms}, \mathrm{p}=0.004)$. Area of $\mathrm{Cz}$ $(-0.7 \pm 0.2 \mathrm{mV} \cdot \mathrm{ms})$ was between $\mathrm{Fz}$ and $\mathrm{Pz}$. When we looked at the negative polarity $100 \mathrm{~ms}$ before the upcoming stimulus (1400 ms after target pulse), their amplitudeswere different $\left(\mathrm{F}_{(2,38)}=4.77, \mathrm{p}<0.014\right.$, epsilon $\left.=0.734\right)$. The amplitude at $\mathrm{Fz}(-3.3 \pm 0.2 \mu \mathrm{V})$ was higher than that at $\mathrm{Pz}(-1.8 \pm 0.1 \mu \mathrm{V}, \mathrm{p}=0.003)$. The amplitude at $\mathrm{Cz}(-2.7 \pm 0.2 \mu \mathrm{V})$ was between that at $\mathrm{Fz}$ and $\mathrm{Pz}$. These results indicate that after every target category, the subjects' EEG shifted to negative polarity before the upcoming stimulus and their degree was almost the same.

\section{Discussion of Experiment 1}

In the present study, we found that RTs for the second instance of repeated tar- 
gets were among the fastest. We found that RTs for the $\mathrm{N}_{1-4} \mathrm{~T}$ category were slower than those for the TT category. These results are attributable to the extremely fast RTs found in TT and the slow RTs found in $\mathrm{N}_{1} \mathrm{~T}$. Thus, we succeeded in inducing the target repetition effect in this study. Our results regarding RT are consistent with previous results [4] [8] [30]. We also found that RTs were fastest for targets immediately preceded by 17 or more non-targets $\left(\mathrm{N}_{\geq 17} \mathrm{~T}\right)$. The phenomenon, however, is not explained by RE.

Oddball tasks had been used to examine the relationship between information processing of targets and non-targets [26] [27] [28] [31]. P3 latencies and amplitudes that we observed in this study were similar to those observed in a study by Gonsalvez et al. [31]. They explained that when the target-to-target interval (TTI) was shorter, P3 latencies were longer and their amplitudes were smaller. They also suggested that target temporal probability rather than global probability is an important factor in determining P3 latency and amplitude.

However, in complete contradiction to our results, Gonsalvez \& Polich [28] observed the slowest RTs for the second instance of repeated targets. Why are the RT results of the second instance of repeated target in the present study different from theirs? We instructed our subjects to respond as quickly and accurately as possible to the target stimuli. Subjects, however, mentioned that the task was quite easy in this study; they probably prioritized quick button press for targets in comparison over accuracy. Verleger [32] also showed that when subjects attended to easy choice response task, stimulus-response association was like a "prepared reflex". Perhaps the results were owing to differing strategies employed by the subjects or instructional styles in the study by Gonsalvez \& Polich [28]. This difference may explain the change in RTs observed between our study and theirs.

After every target category, we observed the EEG shift between $600 \mathrm{~ms}$ and $100 \mathrm{~ms}$ before the upcoming stimulus. The amplitude of this potential was negative, and its amplitude at $100 \mathrm{~ms}$ before the upcoming stimulus (1400 ms after the preceding stimulus) was $-3.3 \mu \mathrm{V}$ at $\mathrm{Fz}$ and $-2.7 \mu \mathrm{V}$ at $\mathrm{Cz}$. These results are similar to the slow potential shifts (SPS) which Desmedt \& Debecker [33] observed when subjects optimized in allocation of vigilance or general attention. Leuthold et al. [15] suggested that CNV comprises two components: an early component distribute frontocentral scalp and a late component distribute centroparietal scalp. Therefore, the question is whether the SPS in the study by Desmet \& Debecker [33] is the same as an early component of CNV that Leuthold et al. [15] had discussed. The target probability was $10 \%$ in our study; it must have been difficult for our subjects to estimate sequential repeated target appearance. The negative shift in the present study was less than $-5 \mu \mathrm{V}$ with frontocentral dominant distribution. These characteristics are rather similar to SPN. The target rarely appeared in this study; thus, the subjects must be aware after target appearance. The subjects generated almost the same negative shift after every target stimuli. Therefore, RTs for the second instance of repeated targets were among the fastest. P3 response was in line with TTI theory; P3 latency of the second instance of repeated targets was the slowest among the target categories. 


\section{Subject and Method for Experiment 2}

Subject and method were the same as Experiment 1. But we analyzed the nontarget data of Experiments 1 in Experiments 2. We examined the ERP components of non-targets and the EEG current shifts for the non-target categories. Subjects, apparatus and materials were the same as Experiment 1.

Each EEG for non-target stimulus was analyzed from $100 \mathrm{~ms}$ before stimulus pulse (pre-stimulus baseline) to $1400 \mathrm{~ms}$ after the non-target stimulus pulse. The maximum number of non-target repetition was 27 . Therefore, we theoretically categorized non-target ERPs from $\mathrm{T}_{1} \mathrm{~N}$ to $\mathrm{T}_{27} \mathrm{~N}$. Such categorizations, however, pose two problems. One is that the results of the 27 non-target ERP categories require too many lines than can be displayed in a single figure, and the other is that the more the non-target stimulus repeats, the less is the number of nontarget EEG responses attained (inversely proportional). To keep the non-target EEG responses stable, we divided non-target EEG repeats from 9 and over into 3 categories: $T_{9-12} \mathrm{~N}(\mathrm{n}=46 \pm 1), \mathrm{T}_{13-16} \mathrm{~N}(\mathrm{n}=49 \pm 1)$, and $\mathrm{T}_{17 \leq} \mathrm{N}(\mathrm{n}=43 \pm 1)$. For instance, $\mathrm{T}_{1} \mathrm{~N}, \mathrm{~T}_{2} \mathrm{~N}$ and $\mathrm{T}_{3} \mathrm{~N}$ represent non-target ERP following one, two and three non-target tone immediately after previous target. Averaging each category of EEG responses, we defined N1 as the negative peak between $50 \mathrm{~ms}$ and 149 $\mathrm{ms}$ after the target or the non-target stimulus pulse. We defined non-target ERP between $200 \mathrm{~ms}$ and $450 \mathrm{~ms}$ after the non-target pulses. We measured the area between the pre-stimulus baseline and non-target ERP from $200 \mathrm{~ms}$ to $450 \mathrm{~ms}$ in accordance with negative and positive polarities.

ERP shift: the pre-stimulus baseline from $600 \mathrm{~ms}$ to $100 \mathrm{~ms}$ before the upcoming stimulus serve as a marker for expectation of the upcoming stimulus. We calculated the degree of ERP shift for each category by integrating the area between the pre-stimulus baseline from $600 \mathrm{~ms}$ to $100 \mathrm{~ms}$ before the upcoming stimulus in accordance with negative and positive polarities.EOG amplitudes over $50 \mu \mathrm{V}$ were treated as artifacts. Commission error was non-target tone button pressing.

A repeated-measures analysis of variance (ANOVA) was used to compare the difference among categories of $\mathrm{T}_{1} \mathrm{~N}, \mathrm{~T}_{2} \mathrm{~N}, \mathrm{~T}_{3} \mathrm{~N}, \mathrm{~T}_{4} \mathrm{~N}, \mathrm{~T}_{5} \mathrm{~N}, \mathrm{~T}_{6} \mathrm{~N}, \mathrm{~T}_{7} \mathrm{~N}, \mathrm{~T}_{8} \mathrm{~N}, \mathrm{~T}_{9-12} \mathrm{~N}$, $T_{13-16} N$, and $T_{17 \_} N$. When ANOVA revealed significant differences, we used Scheffe's analysis to examine the differences between the categories. When we compare the commission error, we grouped categories into 2; those are $\mathrm{T}_{1} \mathrm{~N}$ and the others. Pearson's chi-square test is used to compare the differences in commission errors between $\mathrm{T}_{1} \mathrm{~N}$ and the other non-target categories. Comparison of the area of negativity between $600 \mathrm{~ms}$ and $100 \mathrm{~ms}$ before the upcoming stimulus among the sites (Fz, Cz, and $\mathrm{Pz}$ ), we used Kruskal-Wallis test. $P$ less than 0.05 was considered significance.

\section{Results of Experiment 2}

\subsection{Commission Error to Non-Target Stimulus}

The data from blocks 1 and 2 were analyzed in combination. Combining the first and second blocks of all subjects yielded $0.027 \%$ commission error rates $(8 / 30,080$ 
non-target presentations). Five of the eight commission errors occurred in five subjects after the non-target tone immediately after the target $\left(\mathrm{T}_{1} \mathrm{~N}\right.$; mean $\mathrm{RT}$ \pm SE were $280 \pm 9 \mathrm{~ms}$ ). Another three commission RT were $318 \pm 12 \mathrm{~ms}$, which occurred $\mathrm{T}_{2} \mathrm{~N}, \mathrm{~T}_{4} \mathrm{~N}$ and $\mathrm{T}_{6} \mathrm{~N}$ categories. The results of Pearson's chisquare test indicate that commission errors occurred with significantly higher incidence in the $\mathrm{T}_{1} \mathrm{~N}$ category over the other non-target categories $(\mathrm{p}<0.001)$.

\subsection{N1 Latencies and Amplitudes and ERP Area for the Non-Targets}

Figure 3(a) shows grand averaged EPRs of non-target categories $\left(T_{1} N, T_{2} N\right.$, $\mathrm{T}_{3} \mathrm{~N}, \mathrm{~T}_{4} \mathrm{~N}, \mathrm{~T}_{5} \mathrm{~N}, \mathrm{~T}_{6} \mathrm{~N}, \mathrm{~T}_{7} \mathrm{~N}, \mathrm{~T}_{8} \mathrm{~N}, \mathrm{~T}_{9-12} \mathrm{~N}, \mathrm{~T}_{13-16} \mathrm{~N}$, and $\mathrm{T}_{17 \leq} \mathrm{N}$ ). Over 30 EEG responses were obtained for each non-target category. As shown in Figure 3(a), we do not find any difference among N1 latencies and amplitudes in each non-target category. However, $\mathrm{T}_{1} \mathrm{~N}$ exhibited an ERP of double-positive slow wave between $200 \mathrm{~ms}$ to $450 \mathrm{~ms}$ (DPSW). Figure 3(b-1) shows the change in area of $\mathrm{ERP}$ at Fz. There is a significant difference in area among the categories $\left(\mathrm{F}_{(10,30)}=\right.$ $22.5, \mathrm{p}<0.001$, epsilon $=0.329)$, sites $\left(\mathrm{F}_{(2,38)}=31.3, \mathrm{p}<0.001\right.$, epsilon $\left.=0.751\right)$, and the interaction between categories and sites $\left(\mathrm{F}_{(10,30)}=4.5, \mathrm{p}<0.001\right.$, epsilon $=0.130)$.

Figure $3(\mathrm{~b}-1)$ shows that the area at $\mathrm{Fz}$ for $\mathrm{T}_{1} \mathrm{~N}(0.9 \pm 0.1 \mathrm{mV} \cdot \mathrm{ms})$ and $\mathrm{T}_{2} \mathrm{~N}$ $(0.3 \pm 0.1 \mathrm{mV} \cdot \mathrm{ms})$ differs significantly from the other non-target categories $\left(\mathrm{T}_{17} \mathrm{~N}\right.$ : $\left.-0.4 \pm 0.1 \mathrm{mV} \cdot \mathrm{ms}\right)$. As shown in Figure $3(\mathrm{a}), \mathrm{T}_{1} \mathrm{~N}$ positive peak latency at $\mathrm{Fz}$ is $343 \pm 5 \mathrm{~ms}$ and its amplitude is $7.3 \pm 0.2 \mu \mathrm{V}$.

\subsection{EEG Current Shifts after Each Non-Target Categories}

We examined the areas between $600 \mathrm{~ms}$ and $100 \mathrm{~ms}$ before the upcoming stimulus with the same experimental method used for the target categories. Figure 3(b-2) showed the change in area of ERPs at Fz. There are significant differences in the area of categories $\left(\mathrm{F}_{(10,30)}=52.5, \mathrm{p}<0.001\right.$, epsilon $\left.=0.702\right)$, sites $\left(\mathrm{F}_{(2,38)}=\right.$ $7.4, \mathrm{p}=0.002$, epsilon $=0.924)$, and interaction between categories and sites $\left(\mathrm{F}_{(20,20)}=8.7, \mathrm{p}<0.001\right.$, epsilon $\left.=0.333\right)$. The area at $\mathrm{Fz}$ in accordance with polarity gradually changed from positive $\left(\mathrm{T}_{1} \mathrm{~N}\right.$ : $\left.1.9 \pm 0.1 \mathrm{mV} \cdot \mathrm{ms}\right)$ to negative $\left(\mathrm{T}_{17 \leq} \mathrm{N}:-0.8 \pm 0.1 \mathrm{mV} \cdot \mathrm{ms}\right)$ as the number of preceding non-targets increased. When we looked at the polarity $100 \mathrm{~ms}$ preceding the upcoming stimulus (Figure 3(a)) of $\mathrm{T}_{1} \mathrm{~N}$ and $\mathrm{T}_{17 \leq} \mathrm{N}$, their amplitude at $\mathrm{Fz}(-6.4 \pm 0.2 \mu \mathrm{V})$ was higher than that at $\mathrm{Cz}(-5.2 \pm 0.3 \mu \mathrm{V}, \mathrm{p}=0.022$, Scheffe's analysis $)$ and $\mathrm{Pz}(-3.9 \pm 0.3$ $\mu \mathrm{V}, \mathrm{p}<0.001$ for $\mathrm{Fz}$ and $\mathrm{p}=0.0012$ for $\mathrm{Cz}$ ). These results indicate that subjects generated a negative ERP shift after $\mathrm{T}_{9-12} \mathrm{~N}$ non-targets. The negativity was higher at the frontocentral site than that at the parietal site and gradually increased with the preceding number of non-target repetitions. We compared the $\mathrm{T}_{17 \varsigma} \mathrm{N}$ area of negativity between $600 \mathrm{~ms}$ and $100 \mathrm{~ms}$ before the upcoming stimulus with the TT area at Fz. The $\mathrm{T}_{17 \Sigma} \mathrm{N}$ area was significantly larger at $\mathrm{Fz}(\mathrm{p}<0.001$, Kruskal-Wallis test $)$ and $\mathrm{Cz}(\mathrm{p}=0.023)$ but not at $\mathrm{Pz}$. The result indicated that the topography of negative EEG shifts between non-target and target repetitions 


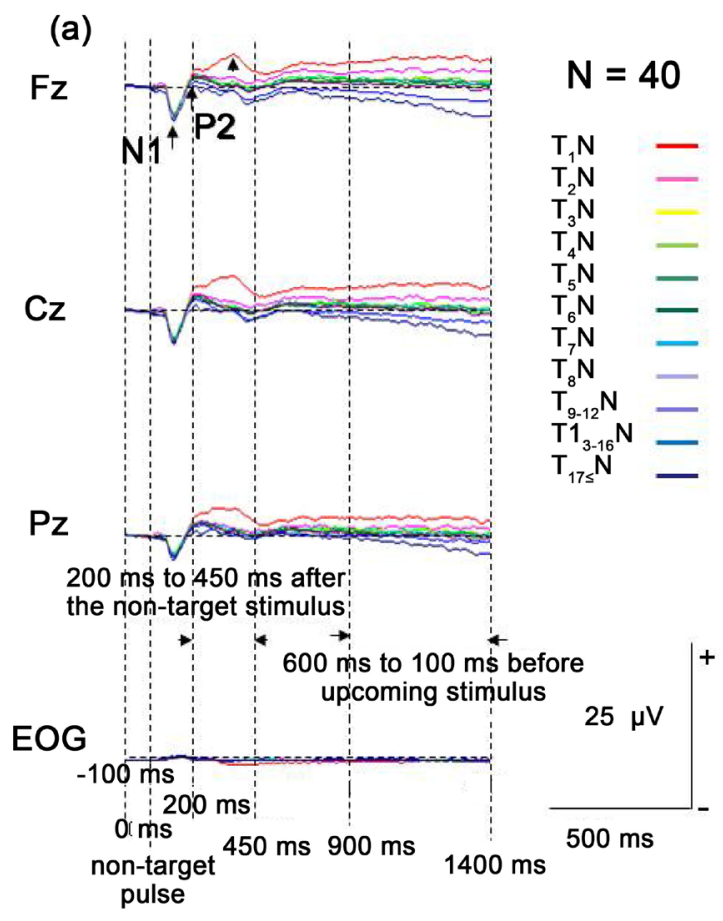

(b-1)

Area of $200 \mathrm{~ms}$ to $\mathbf{4 5 0} \mathrm{ms}$ at $\mathrm{Fz}$

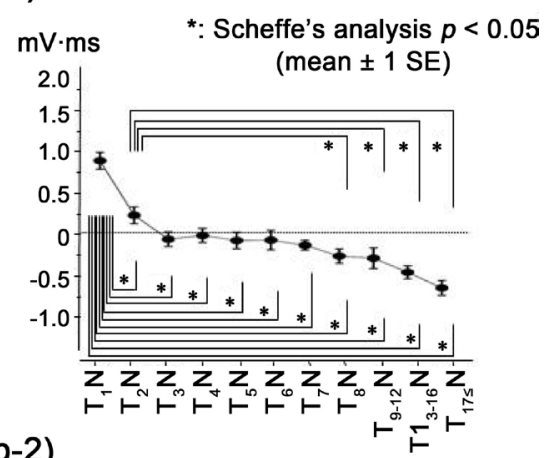

(b-2)

Area of $600 \mathrm{~ms}$ to $100 \mathrm{~ms}$ before $\mathrm{mV} \cdot \mathrm{ms} \quad$ upcoming stimulus at $\mathrm{Fz}$

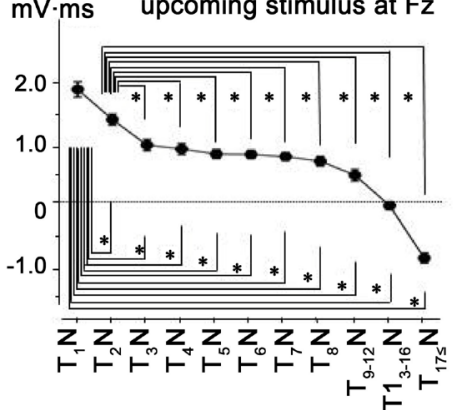

Figure 3. Grand Averaged ERP of non-target stimuli categorized by stimulus repeats. (a) Grand average ERPs $(\mathrm{N}=40)$ for non-target categories and the shifts from $600 \mathrm{~ms}$ to $100 \mathrm{~ms}$ before upcoming stimulus are shown. (b-1) ERPs between $200 \mathrm{~ms}$ and $450 \mathrm{~ms}$ for $\mathrm{T}_{1} \mathrm{~N}$ show a $343 \mathrm{~ms}$ positive peak. It is showed as black triangle in the figure. Its latency was $343 \mathrm{~ms}$ and amplitude $7.3 \mu \mathrm{V}$ at Fz. The peak becomes indistinct suddenly after $\mathrm{T}_{2} \mathrm{~N}$. (b-2) Polarity of the averaged EEG baseline shifts from $600 \mathrm{~ms}$ to $100 \mathrm{~ms}$ before upcoming stimulus is shown. The polarity changes from positive to negative as the number of non-targets increases.

was different.

\subsection{Discussion of Experiment 2}

We found only eight commission errors among the 30,080 non-target trials. We examined this data in more detail; five of these errors occurred after the $T_{1} \mathrm{~N}$ category. These findings are consistent with those of another study showing that commission errors increased after stimulus alternation in choice task [24]. Why did commission errors occur for non-target stimulus immediately after target stimulus?

The grand averaged ERPs of $\mathrm{T}_{1} \mathrm{~N}$ (DPWS) clearly show positive area between $200 \mathrm{~ms}$ and $450 \mathrm{~ms}$ after non-target. That area was frontocentral dominant. The positive area and its peak gradually showed less prominence from $\mathrm{T}_{2} \mathrm{~N}$ to $\mathrm{T}_{175} \mathrm{~N}$. What did these ERPs change mean? P3a, nogoP3, and MMN showed frontocentral dominant positive ERP. P3a appeared under the unattended condition and its latency was shorter than that of P3 [34]. The positive latency of DPSW was $343 \mathrm{~ms}$, which was longer than many other P3s observed in this study. As suggested in Discussion 1, subjects keenly attended and probably prioritized button press after each target stimulus. Thus, DPSW should not be P3a. However, from the result of Experiment1, subjects were aware and willing to press the button. In 
this situation, subjects must withhold the reaction of pressing the button.

EEG current shifts after non-target categories of $\mathrm{T}_{17 \_} \mathrm{N}$ must be $\mathrm{CNV}$ because subjects must have an increased expectation for the upcoming stimulus as target after 9 to 12 non-target repetitions or more in this oddball task, the negative EEG shifts of $100 \mathrm{~ms}$ before the upcoming stimulus were more prominent at $\mathrm{Fz}$ and $\mathrm{Cz}$ sites where the early component of $\mathrm{CNV}$ has its maximum potential, and the voltage of this component is more than $-5 \mu \mathrm{V}$, which Desmedt \& Debecker [33] reported as being compatible with CNV amplitude. When non-target stimuli continued for such a long time, subjects must have expected that upcoming stimulus would be the target. In this case, subjects may withhold pressing the button.

DPSW may be MMN. This ERP is elicited by deviant stimulus embedded in a stream of frequent standards [16] [35]. It reflects the deviation from an inferred memory trace of the standard stimulus. Our results were consistent with those of Sams et al. [34], who used 10\% deviant stimuli (90\% standard) with an ISI of 1 second and concluded that ERPs that appeared following the first deviant are MMN. They also showed that these ERPs disappeared when the same stimuli repeatedly appeared, which also is consistent with our results.

Starr et al. [27] did not find this DPSW issue in their study. We do not know the exact reason for this discrepancy. A possible clue may be found in the instructions provided to subjects pertaining to the target, stimulus sequence, and RT. They did not present the subject target repetition sequence, and the RTs in their study were different those in ours. Figure 5 in their report shows that RT for $\mathrm{T}+3$ (that is equal to $\mathrm{N}_{3} \mathrm{~T}$ in our study) and $\mathrm{T}+4\left(\mathrm{~N}_{4} \mathrm{~T}\right)$ was about $420 \mathrm{~ms}$ and $360 \mathrm{~ms}$, respectively, which is extremely slower than that in our study (323 $\mathrm{ms}$ and $325 \mathrm{~ms}$, respectively). The results suggested that instructions to subjects in their study were different to those in ours.

\section{General Discussion}

There were many reports about ERP P3 and RTs. However, as far as we precisely look for, there are no reports on REs and instructions to subjects. We gathered the results of many previous articles and our experiments; they clearly showed why target RE occurred. It was because although subjects were instructed to react to the target stimulus as quickly and accurately as possible, they prioritized a quick reaction to the target when task was easy [12]. In such situations, they keenly paid attention to target appearances, especially immediately after target appeared. Thus, SPN, which may prime only reaction process, appeared. Subjects may almost complete their decision process before they evaluate the meaning of stimulus [6] [12]. Mechanisms also explain how error rates increase for non-targets immediately after target.

Two questions arise: 1 ) why did the SPN potential $-3.3 \mu \mathrm{V}$ and CNV potential $-6.4 \mu \mathrm{V}$ at $\mathrm{Fz}$ had almost the same effect for the target response times and 2) why $T_{1} \mathrm{~N}$ accompanied $M M N$ but $T_{17 \leq} \mathrm{N}$ did not? For the first question, we strongly speculate based on the results of our topographical analysis that the 
mechanisms underlying SPN and CNV differ from each other. SPN only related to response priming, but $\mathrm{CNV}$ stemmed from attention, sequence probability thinking, and response mechanisms.

The second is that to the best of our knowledge, there have been few studies comparing the degree of RTs and MMN. For $\mathrm{T}_{1} \mathrm{~N}$ condition, subject may assume the non-target tone to be deviant. The reasons are that subjects keenly attend to pressing the button; thus, they have little doubt with the upcoming stimulus being the target. However, in $\mathrm{T}_{17 \leq} \mathrm{N}$ condition, subjects might expect that the target stimulus would be coming soon. In such situation, would subject feel that non-target tone was deviant and they generated the information processing which elicited MMN? We did not explain this processing competently by our results of our experiments. However, we speculated that subjects might feel that non-target stimulus after the long lasing non-target stimuli was not so deviant because the stimuli were in a stream. As shown in Figure 3(a), trace of DPWS was observed at Fz site, but its amplitude was small and the negative area, in comparison with SPN, CNV stemmed from sequence probability, attention, and response strategy; therefore, tone evaluation and response processes would be tightly connected.

Possible limitations of this study: Perhaps the numbers of EEG responses were too small to make stable target ERPs for each subject in this study. However, we assume that this causes few problems for interpreting the results in this study. The reason is that the statistical analysis is consistent with the grand averaged ERP waveforms of Figure 2 and Figure 3. If the average number of target EEG responses for each subject was insufficient, a discrepancy should have occurred between the grand averaged ERP waveforms and results of the ERP latencies and amplitudes.

From these results, we might speculate that: 1) the mechanism underlying the target RE in this auditory oddball task differed from that underlying RSI less than $500 \mathrm{~ms}$, and 2) the mechanisms underlying fast RT for the second instance of the repeated targets and RT of the target that appeared after 17 or more successive non-targets differ. Understanding the mechanisms of why RTs change in sequence and how mistakes occur in task alternation provides key elements for understanding negative EEG shifts in this oddball task with target and non-target ERPs.

\section{Acknowledgements}

The authors would like to thank Enago (www.enago.jp) for the English language review.

\section{Financial Disclosure}

No funding was secured for this study.

\section{Conflicts of Interest}

The authors have no conflicts of interest to disclose. 


\section{References}

[1] Bertelson, P. (1963) S-R Relationships and Reaction Times to New Versus Repeated Signals in a Serial Task. Journal of Experimental Psychology, 65, 478-484. https://doi.org/10.1037/h0047742

[2] Smith, M.C. (1968) Repetition Effect and Short-Term Memory. Journal of Experimental Psychology, 77, 435-439. https://doi.org/10.1037/h0021293

[3] Keele, S.W. (1969) Repetition Effect: A Memory-Dependent Process. Journal of EXperimental Psychology, 80, 243-248. https://doi.org/10.1037/h0021173

[4] Kirby, N.H. (1976) Sequential Effects in Two-Choice Reaction Time: Automatic Facilitation or Subjective Expectancy? Journal of Experimental Psychology, 2, 567-577. https://doi.org/10.1037/0096-1523.2.4.567

[5] Soetens, E., Boer, L.C. and Hueting, J. (1985) Expectancy or Automatic Facilitation? Separating Sequential Effects in Two-Choice Reaction Time. Journal of Experimental Psychology, 11, 598-616. https://doi.org/10.1037/0096-1523.11.5.598

[6] Campbell, K.C. and Proctor, R.W. (1993) Repetition Effects with Categorizable Stimulus and Response Sets. The Journal of Experimental Psychology: Learning, Memory, and Cognition, 19, 1345-1362. https://doi.org/10.1037/0278-7393.19.6.1345

[7] Sommer, W., Leuthold, H. and Soetens, E. (1999) Covert Signs of Expectancy in Serial Reaction Time Tasks Revealed by Event-Related Potentials. Perception \& Psychophysics, 61, 342-353. https://doi.org/10.3758/BF03206892

[8] Hübner, R. and Druey, M.D. (2006) Response Execution, Selection, or Activation: What Is Sufficient for Response-Related Repetition Effects under task Shifting? Psychological Research, 70, 245-261. https://doi.org/10.1007/s00426-005-0219-8

[9] Baldeweg, T. (2006) Repetition Effects to Sounds: Evidence for Predictive Coding in the Auditory System. Trends in Cognitive Sciences, 10, 93-94.

https://doi.org/10.1016/j.tics.2006.01.010

[10] Grill-Spector, K., Henson, R. and Martin, A. (2006) Repetition and the Brain: Neural Models of Stimulus-Specific Effects. Trends in Cognitive Sciences, 10, 14-23. https://doi.org/10.1016/j.tics.2005.11.006

[11] Remington, R.J. (1968) Analysis of Sequential Effects on Choice Reaction Times. Journal of Experimental Psychology, 82, 250-257. https://doi.org/10.1037/h0028122

[12] Schacter, D.L., Dobbins, I.G. and Schnyer, D.M. (2004) Specificity of Priming: A Cognitive Neuroscience Perspective. Nature Reviews Neuroscience, 5, 853-862. https://doi.org/10.1038/nrn1534

[13] Brunia, C.H.M. (1993) Waiting in Readiness: Gating in Attention and Motor Preparation. Psychophysiology, 30, 327-339. https://doi.org/10.1111/j.1469-8986.1993.tb02054.x

[14] Brunia, C.H.M. (2003) CNV and SPN: Indices of Anticipatory Behavior. In: Jahanshahi, M. and Hallett, M., Eds., The Bereitschaftspotential, Kluwer/Plenum, New York, 207-228. https://doi.org/10.1007/978-1-4615-0189-3_13

[15] Leuthold, H., Sommer, W. and Ulrich, R. (2004) Preparing for Action: Inferences from CNV and LRP. Journal of Psychophysiology, 18, 77-88.

https://doi.org/10.1027/0269-8803.18.23.77

[16] Garrido, M.I., Kilner, J.M., Stephan, K.E. and Friston, K.J. (2009) The Mismatchnegativity: A Review of Underlying Mechanisms. Clinical Neurophysiology, 20, 453463. https://doi.org/10.1016/j.clinph.2008.11.029

[17] Haenschel, C., Vernon, D.J., Dwivedi, P., Gruzelier, J.H. and Baldeweg, T. (2005) Event-Related Brain Potential Correlates of Human Auditory Sensory MemoryTrace Formation. Journal of Neuroscience, 25, 10494-10501. 
https://doi.org/10.1523/JNEUROSCI.1227-05.2005

[18] Kutas, M., McCarthy, G. and Donchin, E. (1977) Augmenting Mental Chronometry: The p300 as a Measure of Stimulus Evaluation Time. Science, 197, 792-795. https://doi.org/10.1126/science.887923

[19] Ritter, W., Simson, R., Vaughan Jr., H.G. and Friedman, D. (1979) A Brain Event Related to the Making of a Sensory Discrimination. Science, 203, 1358-1361. https://doi.org/10.1126/science.424760

[20] Magliero, A., Bashore, T.R., Coles, M.G.H. and Donchin, E. (1984) On the Dependence of P300 Latency on Stimulus Evaluation Processes. Psychophysiology, 21, 171-186. https://doi.org/10.1111/j.1469-8986.1984.tb00201.x

[21] Barry, R.J. (2009) Evoked Activity and EEG Phase Resetting in the Genesis of Auditory Go/NoGoERPs. Biological Psychology, 80, 292-299. https://doi.org/10.1016/j.biopsycho.2008.10.009

[22] Lange, F., Rösler, F. and Röder, B. (2003) Early Processing Stages Are Modulated When Auditory Stimuli Are Presented at an Attended Moment in Time: An EventRelated Potential Study. Psychophysiology, 40, 806-817. https://doi.org/10.1111/1469-8986.00081

[23] Katayama, J. and Polich, J. (1998) Stimulus Context Determines P3a and P3b. Psychophysiology, 35, 23-33. https://doi.org/10.1111/1469-8986.3510023

[24] Smith, J.C., Smith, E.A., Provost, A.L. and Heathecote, A. (2010) Sequence Effects Support the Conflict Theory of N2 and P3 in the Go/NoGo Task. International Journal of Psychophysiology, 75, 217-226. https://doi.org/10.1016/j.ijpsycho.2009.11.002

[25] Duncan-Johnson, C. and Donchin, E. (1977) On Quantifying Surprise: The Variation in Event-Related Potentials with Subjective Probability. Psychophysiology, 14, 456-467. https://doi.org/10.1111/j.1469-8986.1977.tb01312.x

[26] Starr, A., Sandroni, P. and Michalewski, H.J. (1995) Readiness to Respond in a Target Detection Task: Pre- and Post-Stimulus Event-Related Potentials in Normal Subjects. Electroencephalography and Clinical Neurophysiology, 96, 76-92. https://doi.org/10.1016/0013-4694(94)00162-E

[27] Starr, A., Aguinaldo, T., Roe, M. and Michalewski, H.J. (1997) Sequential Changes of Auditory Processing during Target Detection: Motor Responding versus Mental Counting. Electroencephalography and Clinical Neurophysiology, 105, 201-212. https://doi.org/10.1016/S0924-980X(97)00016-7

[28] Gonsalvez, C.J. and Polich, J. (2002) P300 Amplitude Is Determined by Target-toTarget Interval. Psychophysiology, 39, 388-396. https://doi.org/10.1017/S0048577201393137

[29] Picton, T.W. (1992) The P300 Wave of the Human Event-Related Potential. Journal of Clinical Neurophysiology, 9, 456-479. https://doi.org/10.1097/00004691-199210000-00002

[30] Matt, J., Leuthold, H. and Sommer, W. (1992) Differential Effects of Voluntary Expectancies on Reaction Times and Event-Related Potentials: Evidence for Automatic and Controlled Expectancies. The Journal of Experimental Psychology: Learning, Memory, and Cognition, 18, 810-822. https://doi.org/10.1037/0278-7393.18.4.810

[31] Gonsalvez, C.J., Gordon, E., Grayson, S., Barry, R.J., Lazzaro, I. and Bahramali, H. (1999) Is the Target-to-Target Interval a Critical Determinant of P3 Amplitude? Psychophysiology, 36, 643-654. https://doi.org/10.1111/1469-8986.3650643

[32] Verleger, R. (1997) On the Utility of P3 Latency as an Index of Mental Chronometry. Psychophysiology, 34, 131-156. 
https://doi.org/10.1111/j.1469-8986.1997.tb02125.x

[33] Desmedt, J.E. and Debecker, J. (1979) Slow Potential Shifts and Decision P350 Interaction in Tasks with Random Sequences of Near-Threshold Clicks and Finger Stimuli Delivered at Regular Intervals. Electroencephalography and Clinical Neurophysiology, 47, 671-679. https://doi.org/10.1016/0013-4694(79)90294-3

[34] Sams, M., Alho, K. and Näätänen, R. (1984) Short-Term Habituation and Dishabituation of the Mismatch Negativity of the ERP. Psychophysiology, 21, 434-441. https://doi.org/10.1111/j.1469-8986.1984.tb00223.x

[35] Wacongne, C., Changeux, J.P. and Dehaene, S. (2012) A Neuronal Model of Predictive Coding Accounting for the Mismatch Negativity. Journal of Neuroscience, 32, 3665-3678. https://doi.org/10.1523/JNEUROSCI.5003-11.2012

Submit or recommend next manuscript to SCIRP and we will provide best service for you:

Accepting pre-submission inquiries through Email, Facebook, LinkedIn, Twitter, etc. A wide selection of journals (inclusive of 9 subjects, more than 200 journals)

Providing 24-hour high-quality service

User-friendly online submission system

Fair and swift peer-review system

Efficient typesetting and proofreading procedure

Display of the result of downloads and visits, as well as the number of cited articles

Maximum dissemination of your research work

Submit your manuscript at: http://papersubmission.scirp.org/

Or contact jbbs@scirp.org 